\title{
The Tortuous Routes of Migrating Neurons in the Folding Neocortex
}

\author{
Marta Florio, Takashi Namba, and Katherine Long \\ Max Planck Institute of Molecular Cell Biology and Genetics, 01307 Dresden, Germany \\ Review of Gertz and Kriegstein
}

The function of the cerebral cortex depends on proper circuit assembly, which requires spatiotemporal coordination of multiple developmental events. During neurogenesis, vast numbers of pyramidal neurons are born in the ventricular zone (VZ) and subventricular zone (SVZ), deep within the dorsal telencephalon. Young neurons must then migrate outward from their birthplaces to reach their target positions in the cortical plate $(\mathrm{CP})$ : the prospective cortex (Kriegstein and Noctor, 2004). As a result of this migration, neurons stratify horizontally into distinct layers (Franco and Muller, 2013) and align vertically into columns, which are parceled into different cytoarchitectural areas (Mountcastle, 1997). How this $3 \mathrm{D}$ topology is sculpted during cortical development, and how evolution has modified its basic design, has been the focus of intense research in the last few decades. A longstanding problem is whether and how neuronal migration changed during the evolutionary expansion of the gyrencephalic neocortex to allow greater numbers of neurons to travel longer distances toward their target areas in the enlarging and folding $\mathrm{CP}$.

All pyramidal neurons descend from cell divisions of radial glial cells (RGs) in the VZ, typically through various types of basal (or

Received Dec. 27, 2015; revised Feb. 3, 2016; accepted Feb. 6, 2016. The authors declare no competing financial interests.

Correspondence should be addressed to Dr. Marta Florio, Max Planck

Institute of Molecular Cell Biology and Genetics, Pfotenhauerstrasse 108, 01307 Dresden, Germany. E-mail: florio@mpi-cbg.de.

DOI:10.1523/JNEUROSCI.4628-15.2016

Copyright $\odot 2016$ the authors $\quad 0270-6474 / 16 / 363887-03 \$ 15.00 / 0$ intermediate) progenitors in the SVZ (Florio and Huttner, 2014). RGs are epitheliallike cells that extend a long fiber from the VZ to the basal lamina overlying the CP. The radial unit model of corticogenesis posits that clonally related neurons migrate in order of birth along the radial fiber scaffold of their RG parent to settle within the CP in a columnar array (Rakic, 1995; Noctor et al., 2001). According to this model of corticogenesis, a topological map is superimposed onto the germinal zones (Rakic, 1988), such that the birthdate and birthplace of a given neuron largely predict its laminar and areal fate, respectively.

Throughout evolution, the correlation between neuronal birthdate and laminar fate appears to hold: in all mammalian species, pyramidal neurons are born following an inside-out temporal sequence, with neurons born earlier occupying the deeper layers and later-born neurons settling in more superficial layers (Angevine and Sidman, 1961; Nadarajah and Parnavelas, 2002). The relationship between neuron birthplace and areal fate, however, appears to be looser. In rodents, which have a smooth (lissencephalic) neocortex, neuronal clones arrange in vertical clusters, consistent with a predominantly radial mode of neuronal migration to the CP (Gao et al., 2014) and a near point-to-point mapping between $\mathrm{VZ}$ and CP. However, in the ferret (a gyrencephalic carnivore), clonally related neurons show little tendency to cluster, but rather disperse widely throughout the neocortex, seemingly unrestricted to areal boundaries (Reid et al., 1997; Ware et al.,
1999). Moreover, a considerable degree of radial fiber divergence accompanies cortical expansion and folding, with RG fibers displaying a fanned array at sites of developing folds, being more obliquely angled at sites of developing gyri compared with sulci (Reillo et al., 2011). These observations led to the hypothesis that in gyrencephalic species, pyramidal neurons do not follow strictly radial migratory routes to reach the CP and that changes in the topology of the RG scaffold may modify the trajectory of migrating neurons by driving them to spread tangentially (Lui et al., 2011; Reillo et al., 2011; Borrell and Reillo, 2012).

A recent report in The Journal of Neuroscience (Gertz and Kriegstein, 2015) provided direct evidence to support this hypothesis, bringing new cellular insights into the evolution of neuronal migration in the folding neocortex. To study neuronal migration during ferret corticogenesis and its relationship with gyrogenesis, the authors examined migrating upper-layer neurons before and after the onset of cerebral folding [postnatal day (P)2 and P7, respectively]. Organotypic slices of ferret neocortex were infected with a GFP-adeno-associated virus that preferentially targets postmitotic cells, thus robustly labeling migrating neurons. Live imaging was then performed and migration of individual neurons was tracked over time. Cell-type identity was assessed after imaging by immunostaining for Satb2, a marker of upper-layer neurons. These experiments showed that, as in rodents, neurons born at earlier stages of upper-layer neurogenesis in ferrets migrate radially 
from the germinal zones toward the CP. However, at the onset of cortical folding, pyramidal neurons follow increasingly tortuous trajectories when traversing the germinal zones, often turning and deviating from their original orientation toward the CP. Next, the authors used dual-color live imaging to differentially label migrating neurons and RG fibers at the onset of cortical folding. Surprisingly, neurons were observed "swinging" through the germinal zones and switching between several different RG fibers on their way to the CP, revealing a novel mode by which lateborn upper-layer neurons can disperse tangentially in the folding cortex.

Importantly, this stage-dependent change in migratory behavior was accompanied by changes in neuronal polarization. In lissencephalic rodents, newborn neurons in the germinal zones generally display a multipolar morphology and dynamic neurites. Subsequently, young neurons extend stable leading and trailing processes (the future dendrite and axon, respectively) and become bipolar before migrating toward the CP along the radial scaffold (Cooper, 2014; Namba et al., 2015). Gertz and Kriegstein (2015) observed that neuronal migration before gyrification had started was similar to that in the rodent and consistent with RGguided, CP-directed locomotion. In contrast, after the onset of gyrification, when neurons migrated along more tortuous paths, their trailing process thickened and transformed into a leading process, whereas the former leading process became the new trailing process. Thus, while these neurons look bipolar and have a clear frontrear polarity, they have not yet established a stable axon-dendrite polarity. This suggests that the polarization process of migrating neurons differs before and after the start of gyrification, and that neuronal polarization in lissencephalic versus gyrencephalic species may be distinct.

Interestingly, neurons were also observed to migrate along and switch between radial fibers of the so-called basal (or outer) RG (bRG): the most abundant and proliferative type of basal progenitor in the SVZ of large-brained, notably gyrencephalic, species (Fietz et al., 2010; Hansen et al., 2010; Reillo et al., 2011). bRG are thought to be a key adaptation during evolutionary cortical expansion because at one time they greatly amplify neuronal output (Lui et al., 2011; Florio and Huttner, 2014) and their ascending, diverging fibers provide a potential scaffold for neuronal migration and tangential dispersion (Lui et al., 2011; Reillo et al., 2011, Borrell and Reillo, 2012; Lewitus et al., 2013). Moreover, bRG fibers in the primate
(Betizeau et al., 2013) and ferret (Gertz et al., 2014) are highly dynamic, continuously extending and retracting in both apical and basal directions. This versatile fiber behavior could therefore create a constantly changing, discontinuous scaffold for neuronal migration, further increasing the variability of migratory behaviors in the folding neocortex.

A few main questions remain unanswered, which invite further investigations: are the observed patterns of neuronal migration characteristic of the folding neocortex as a whole, or rather is this tortuous migration specific to presumptive sites of folding? How do migrating neurons behave in prospective sulcal regions, where RG fibers tracts are more similar to those in the developing lissencephalic cortex (Reillo et al., 2011)? To what extent are neurons migrating along RG fibers, including bRG, clonally related in prospective gyral versus sulcal regions? Answering these questions may provide a better understanding of the patterns of tangential dispersion of pyramidal neurons during cortical development and evolution.

Yet the findings of Gertz and Kriegstein (2015) bring a new perspective in which to address the problem: is the birthplace of a neuron predictive of its areal fate in the cortical cytoarchitecture? Two contrasting views of how cortical areas are specified are the protomap and the protocortex hypotheses. The protomap hypothesis, building on the radial unit model, postulates that different cytoarchitectural subdivisions are specified during neurogenesis, before neuronal connections are made (Dehay et al., 1993; Polleux et al., 1997a,b). Neurons within each cortical area are thus inherently different, as their areal fate is already specified in the germinal zones (Rakic, 1978, 1988). According to the protocortex hypothesis, however, little fate specification occurs during neurogenesis. Rather, the cortical anlage is initially a tabula rasa composed of equivalent populations of neuronal progenitors, with area-specific neuronal differentiation being primarily due to environmental (e.g., connectivity) cues (O'Leary, 1989). The patterns of tangential dispersion observed by Gertz and Kriegstein (2015) suggest that these two models of fate specification may in fact coexist. Earliest-born deep-layer neurons, fated to connect to extra-cortical brain areas, may be incorporated into the cortical network in a more stereotypical fashion, being more strictly constrained to radial migration. Conversely, latest-born upper-layer neurons, destined to establish connections within the neocortex, might travel longer distances away from their birthplace and from one another, being incorporated into distinct and distant cortical columns. Thus, only the latest-born upper-layer neurons are likely to migrate away from their protomap and cross their presumptive areal boundaries.

Future studies should aim to confirm whether the neuronal migratory dynamics observed in the developing ferret cortex are widespread among gyrencephalic species. Should this be the case, the tangential dispersion of a subset of upper-layer neurons, and their departure from the parental RG scaffold, may help to explain the more varied and complex neuronal networks characteristic of the gyrencephalic neocortex. One intriguing possibility is that the "swinging" migration observed by Gertz and Kriegstein (2015) is a mechanism inherently stochastic, allowing neurons born in distinct regions to intermingle and enabling neurons born in the same region to occupy different positions in the mature cortex. Species, and even individuals, may differ by the degree of dispersion of the youngest upper-layer neurons at the tip of their cortical columns, introducing an element of chance and uniqueness to the deterministic process of cortical assembly.

\section{References}

Angevine JB Jr, Sidman RL (1961) Autoradiographic study of cell migration during histogenesis of cerebral cortex in the mouse. Nature 192:766-768. CrossRef Medline

Betizeau M, Cortay V, Patti D, Pfister S, Gautier E, Bellemin-Ménard A, Afanassieff M, Huissoud C, Douglas RJ, Kennedy H, Dehay C (2013) Precursor diversity and complexity of lineage relationships in the outer subventricular zone of the primate. Neuron 80:442-457. CrossRef Medline

Borrell V, Reillo I (2012) Emerging roles of neural stem cells in cerebral cortex development and evolution. Dev Neurobiol 72:955-971. CrossRef Medline

Cooper JA (2014) Molecules and mechanisms that regulate multipolar migration in the intermediate zone. Front Cell Neurosci 8:386. CrossRef Medline

Dehay C, Giroud P, Berland M, Smart I, Kennedy H (1993) Modulation of the cell cycle contributes to the parcellation of the primate visual cortex. Nature 366:464-466. CrossRef Medline

Fietz SA, Kelava I, Vogt J, Wilsch-Bräuninger M, Stenzel D, Fish JL, Corbeil D, Riehn A, Distler W, Nitsch R, Huttner WB (2010) OSVZ progenitors of human and ferret neocortex are epithelial-like and expand by integrin signaling. Nat Neurosci 13:690-699. CrossRef Medline

Florio M, Huttner WB (2014) Neural progenitors, neurogenesis and the evolution of the neocortex. Development 141:2182-2194. CrossRef Medline

Franco SJ, Müller U (2013) Shaping our minds: stem and progenitor cell diversity in the 
mammalian neocortex. Neuron 77:19-34. CrossRef Medline

Gao P, Postiglione MP, Krieger TG, Hernandez L, Wang C, Han Z, Streicher C, Papusheva E, Insolera R, Chugh K, Kodish O, Huang K, Simons BD, Luo L, Hippenmeyer S, Shi SH (2014) Deterministic progenitor behavior and unitary production of neurons in the neocortex. Cell 159:775-788. CrossRef Medline

Gertz CC, Kriegstein AR (2015) Neuronal migration dynamics in the developing ferret cortex. J Neurosci 35:14307-14315. CrossRef Medline

Gertz CC, Lui JH, LaMonica BE, Wang X, Kriegstein AR (2014) Diverse behaviors of outer radial glia in developing ferret and human cortex. J Neurosci 34:2559-2570. CrossRef Medline

Hansen DV, Lui JH, Parker PR, Kriegstein AR (2010) Neurogenic radial glia in the outer subventricular zone of human neocortex. Nature 464:554-561. CrossRef Medline

Kriegstein AR, Noctor SC (2004) Patterns of neuronal migration in the embryonic cortex. Trends Neurosci 27:392-399. CrossRef Medline

Lewitus E, Kelava I, Huttner WB (2013) Conical expansion of the outer subventricular zone and the role of neocortical folding in evolu- tion and development. Front Hum Neurosci 7:424. CrossRef Medline

Lui JH, Hansen DV, Kriegstein AR (2011) Development and evolution of the human neocortex. Cell 146:18-36. CrossRef Medline

Mountcastle VB (1997) The columnar organization of the neocortex. Brain 120:701-722. CrossRef Medline

Nadarajah B, Parnavelas JG (2002) Modes of neuronal migration in the developing cerebral cortex. Nat Rev Neurosci 3:423-432. CrossRef Medline

Namba T, Funahashi Y, Nakamuta S, Xu C, Takano T, Kaibuchi K (2015) Extracellular and intracellular signaling for neuronal polarity. Physiol Rev 95:995-1024. CrossRef Medline

Noctor SC, Flint AC, Weissman TA, Dammerman RS, Kriegstein AR (2001) Neurons derived from radial glial cells establish radial units in neocortex. Nature 409:714-720. CrossRef Medline

O'Leary DD (1989) Do cortical areas emerge from a protocortex? Trends Neurosci 12:400406. CrossRef Medline

Polleux F, Dehay C, Kennedy H (1997a) The timetable of laminar neurogenesis contributes to the specification of cortical areas in mouse isocortex. J Comp Neurol 385:95-116. CrossRef Medline
Polleux F, Dehay C, Moraillon B, Kennedy H (1997b) Regulation of neuroblast cell-cycle kinetics plays a crucial role in the generation of unique features of neocortical areas. J Neurosci 17:7763-7783. Medline

Rakic P (1978) Neuronal migration and contact guidance in the primate telencephalon. Postgrad Med J 54:25-40. Medline

Rakic P (1988) Specification of cerebral cortical areas. Science 241:170-176. CrossRef Medline

Rakic P (1995) A small step for the cell, a giant leap for mankind: a hypothesis of neocortical expansion during evolution. Trends Neurosci 18:383-388. CrossRef Medline

Reid CB, Tavazoie SF, Walsh CA (1997) Clonal dispersion and evidence for asymmetric cell division in ferret cortex. Development 124: 2441-2450. Medline

Reillo I, de Juan Romero C, García-Cabezas MÁ, Borrell V (2011) A role for intermediate radial glia in the tangential expansion of the mammalian cerebral cortex. Cereb Cortex 21: 1674-1694. CrossRef Medline

Ware ML, Tavazoie SF, Reid CB, Walsh CA (1999) Coexistence of widespread clones and large radial clones in early embryonic ferret cortex. Cereb Cortex 9:636-645. CrossRef Medline 